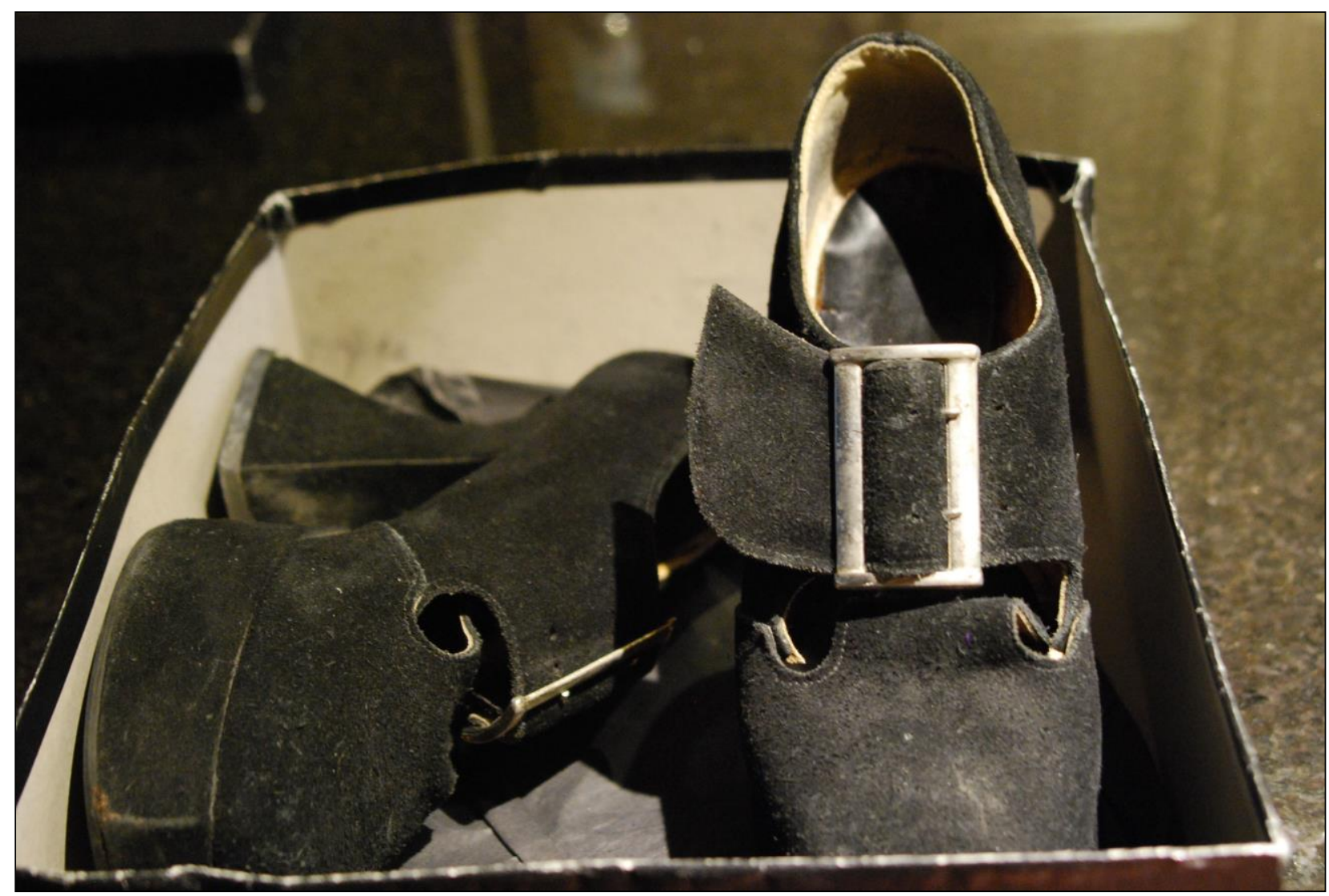

Photo credit: Francesca D’Angelo

\title{
My Past As Retold By My "Munsters"
}

\author{
Francesca D'Angelo \\ York University, Canada
}

At 16, when the make-up artist I was modeling for asked me how I wanted to get paid, I answered with, "the Munsters by Fluevog that Madonna and Dee-Lite are wearing, of course!", like any good teen that doesn't fully understand the value of money.

I received these shoes in 1993, as retribution for a photo shoot I had done for a hairdresser and make-up artist friend of mine. I remember I didn't want money because at the time, at 16, my mom had absolute authority over my wages (she actually landed me the job with her hairdresser), and the only value money was to have for me, according to her, was as savings! So I told him if I wanted those $\$ 400$ shoes it was the only way for me to have them. He just HAD to buy them for me. My mom would have never let me purchase them.

My poor mom... I'll never forget her wide-eyed look as I strode in wearing my new shoes, which raised me to a staggering 5'12", paired with my new crushed velvet cat-suit, make-up and short blonde hair; as she stared up at me, for a split moment, I think she may not have recognized me, or maybe simply realized that I had literally grown up. Her expression that night - a kind of look of 
acknowledgment - paired with my new stature seemed to all signal, in the matter of moments, the splitting of our paths. That small act of sartorial anarchy, I think was doubly wounding for her as it underlined my independence from not only her financial upkeep but her rule as well. I was finally making my break with teenage life and entering young adulthood.

However, now, looking back, I recall that moment as both a kind of gain as well as a significant loss...

Wow, do these shoes bring me way back...

I love those shoes, and still manage to dredge them up every so often, but sadly only for amusement and mockery now as I end up wearing them at Halloween parties. But, there was a time when I took those shoes very seriously. They were like my amulets during high school. They set me apart from the others, they signaled my independent, adult-like life outside of the institutional secondary school walls. They signaled my diva-ness!

I remember my first day wearing them in high school. It was civvies day, and I was sitting in Geography class, when I got called down to the principal's office. I was totally perplexed, couldn't figure out what I had done. So I strut my stuff down to the office keeping my cool while of course freaking out. When I got to the office all the secretaries were lined up at the counter waiting for me. They had called me down because they wanted to check out my shoes! One of them noticed my ensemble and had to share with the others. Not only were the shoes out there, but it also didn't help that I had paired them with my to-die-for Pam Chorley crushed velvet cat suit with stirrups, oh ya, and that I was sporting Madonna's True Blue look with boyishly short platinum blonde hair. I will never forget that combo - that combo would become my uniform for the next five years minus the blonde hair which would go through a number of other permutations. I was so out there that I recall a year later, while sitting in Accounting class, in my anonymous school uniform, chatting away with a couple of other students, one of the guys says, "Hey, remember that girl that looked like Madonna, with those crazy shoes? Whatever happened to her?" All wide-eyed and confused I squealed, "you're kidding, right? That was me!” They all laughed. It felt like I was having an out of body experience.

Thinking back ... Oh, how I MISS those shoes! If I had the space to do so I would showcase them in my house like some museum relic in one of those encased glass pedestals. I remember reading once about a woman who would arrange a selection of her shoes in her drawing room, like sculptures. And that her visitors would be all perplexed walking in to this display of shoes, because, as she put it, "this irruption of intimacy in a place devoted to the demonstration of social status (the drawing room) was rather unsettling at first".

But, doing so would only remind me of how far that memory, those shoes are from my current reality. That's what I miss the most, the memory of those shoes. They were my youth, and looking at them I can't help but feel that longing, while also feeling the drab of what my wardrobe 
has become - its conservativeness and its frugalness, because there is no way that I would pay $\$ 400$ today for a pair of shoes just to go out and party. That's probably also because I wouldn't make much use of them since partying is usually the last thing on my agenda these days (although I should add that I did recently spend $\$ 225$ on a pair of Twin Set platforms that I've only worn a total of 5 times so far). In fact, I don't think I can recall a shoe I used more than my Fluevogs, and the signs of their labor are evident in their disfigurations, discolorations and scuffs as they morphed into being my banal everyday shoe - you know that shoe you put on for comfort, that is so familiar to you that it registers all the nooks and crannies of your feet so perfectly that it becomes your foot, your walk, your look - they were that shoe for me. I wore them not only while partying it up, but also to work at this very trendy hair salon that expected staff to look stylish (sadly, my current profession does not make room for aesthetic expression and vagaries in the same way).

Wearing them was like slipping on this super cool identity. Like the power of Dorothy's shoes, with the click of my heels, I would find myself getting in to some of the hottest 90s dance clubs in Chicago, New York, Montreal, and in Toronto's The Barn. And somehow, the minute I took off those shoes, I also sadly took off the diva in me. Kind of like what Lynda Carter must have felt when she had to hang up the golden lassos.

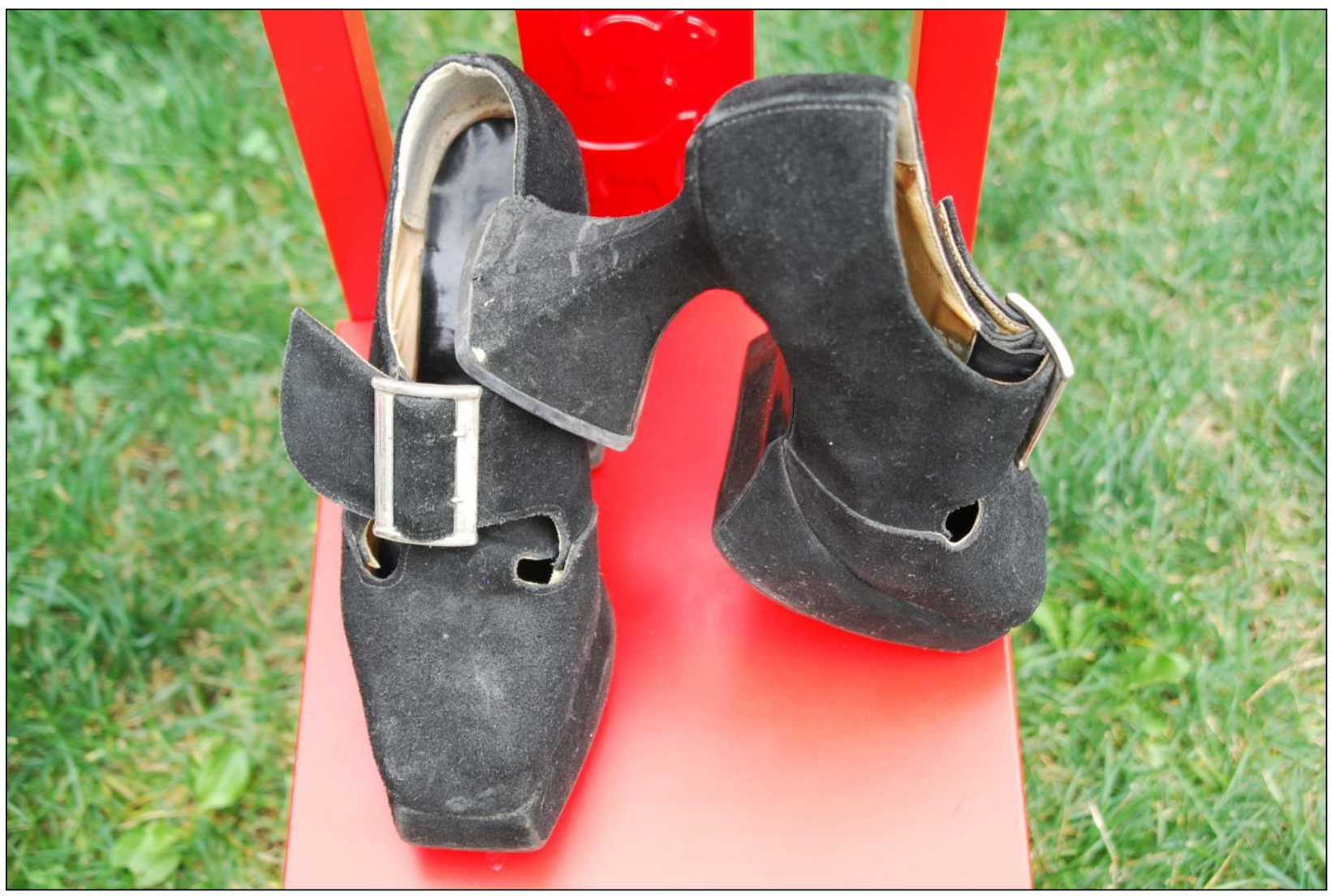

Photo credit: Francesca D'Angelo

But, rather than lament their loss, and my youth, I do want to celebrate this shoe and its design. As an object, I miss them as well because they were truly unique, such an interesting design. So architectural. Not only did I love their witch-like charm, with their pilgrim buckle, but I felt like I 
was also standing on major architectural feats (excuse the pun). And I also loved how they seemed to bridge time by appearing almost Victorian-like, while also being modern with its platform sole. Such futuristic vintage if I could coin that. It would only take me doing my dissertation on stiletto heels for me to realize that the platform of those shoes also beckoned one other object in time: the Renaissance chopine. So my Fluevog's were really a kind of timeless shoe. I wish I could only find the time to wear them!

And now as I pack them back away in their little carton caskets, I feel a pang of regret as a part of me gets buried with them as well. A part of me I may have long forgotten had it not been for this writing exercise that has reminded me of the special archival value of certain things.

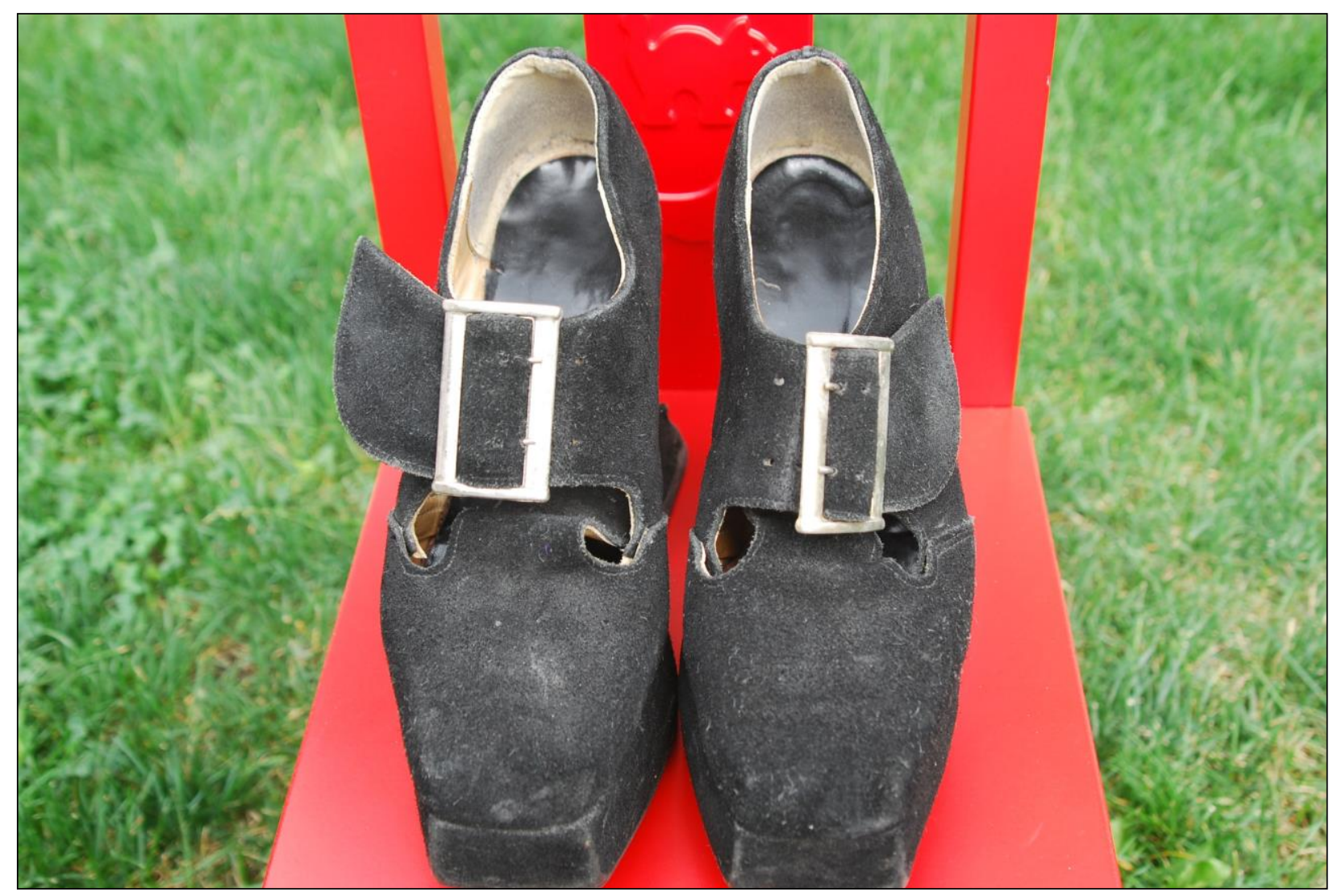

Photo credit: Francesca D’Angelo 
TranscUlturAl, vol. 8.1 (2016), 13-17.

http://ejournals.library.ualberta.ca/index.php/TC

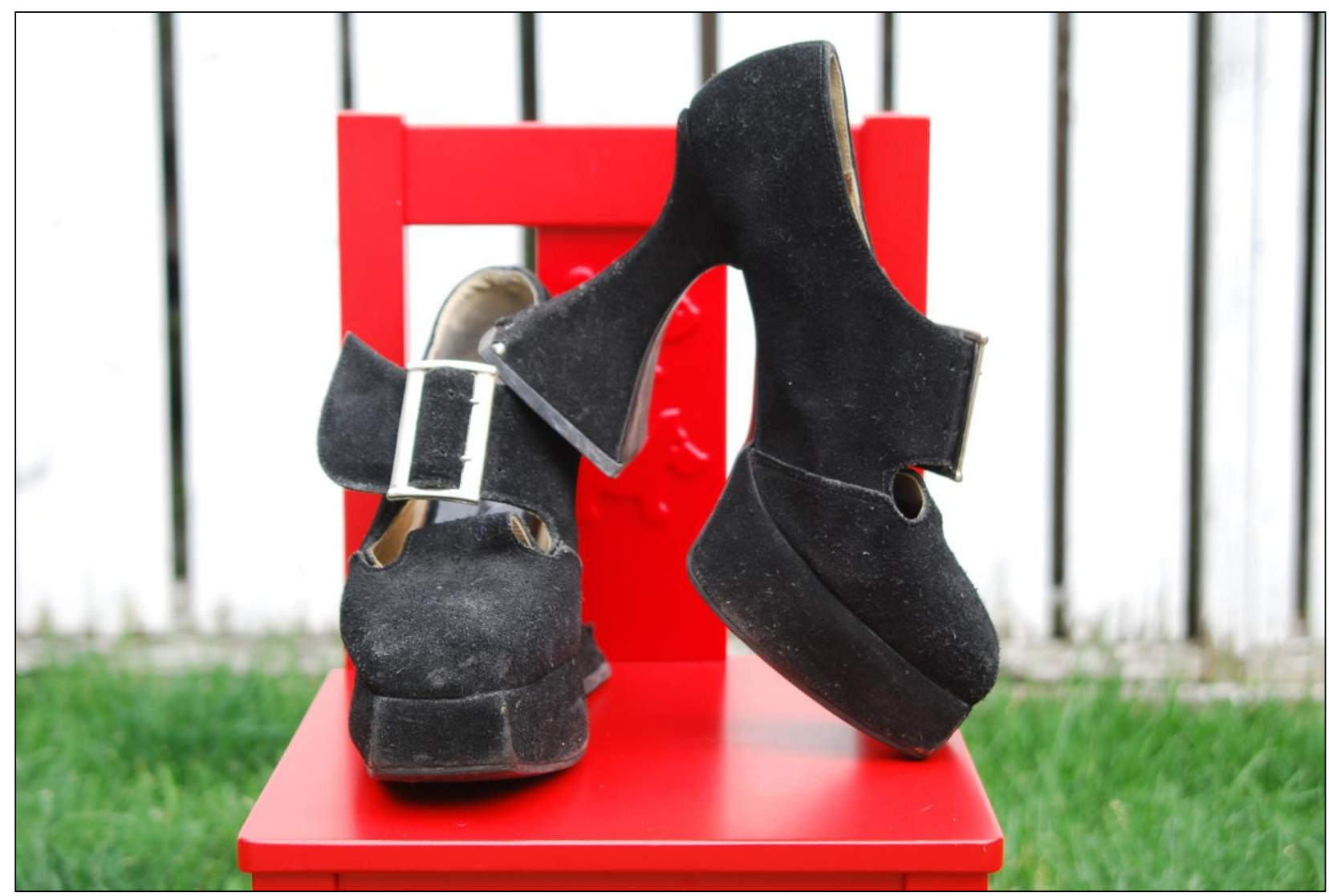

Photo credit: Francesca D’Angelo 